\section{Sero-prevalence and risk fac- tors of HIV/AIDS among long distance commercial drivers in Kano State, Nigeria}

\author{
Usman Sunusi Usman, 1,2 \\ Yusuf Abdu Misau, ${ }^{3}$ \\ Abubakar Muhammad Kurfi, ${ }^{4}$ \\ Umar Lawal Bello, ${ }^{5}$ \\ Ibrahim Adam Abdullahi ${ }^{1}$ \\ ${ }^{1}$ Department of Public Health, Faculty \\ of Basic Health Sciences, Bauchi State \\ University, Gadau; ${ }^{2}$ Department of \\ Public Health, Federal Medical Centre \\ Birnin Kudu; ${ }^{3}$ Department of \\ Community Medicine, Abubakar \\ Tafawa Balewa University of \\ Technology, Bauchi; ${ }^{4}$ National Health \\ Insurance Scheme, Kaduna Zonal \\ Office; ${ }^{5}$ Department of Nursing \\ Sciences, College of Health Sciences, \\ Bayero University Kano, Nigeria
}

\begin{abstract}
Migration and mobility have contributed significantly in the spread of HumanImmunodeficiency Virus (HIV) globally: more especially among transport corridors. Identifying risk factors of HIV among long distance drivers (LDDs) could provide strategies for more effective preventive intervention. This was a cross-sectional descriptive study design that used multistage sampling technique to select four hundred and thirty-four study participants. An interviewer-administered questionnaire was used to collect information and blood for HIV testing. The mean and standard deviation of age of the respondents were $42.3 \pm 11.2$ years. The sero-prevalence of HIV was $12.5 \%$ (95\%CI: $8.8-16.3 \%)$. On adjusting for confounding effect using logistic regression analysis, the risk factors for HIV were marital status of single [AOR $=4.25$; $(95 \% \mathrm{CI}: 1.97-9.31)]$ and separated $[\mathrm{AOR}=6.07$; $(95 \% \mathrm{CI}: 5.26-16.45)]$, monthly income $[>100,000.00 \mathrm{AOR}=6.11$; (95\%CI: 1.53-41.97)] and history of extramarital sex [AOR $=4.01$; (95\% CI: 6.0710.43)]. Establishment of clinic for treatment of sexually transmitted diseases in a strategic location, scaling up of condom distribution, and effective behavioural change communication were recommended in order to reduce the risk of acquiring HIV infection.
\end{abstract}

\section{Introduction}

Globally, migration and mobility of people have exacerbated HIV/AIDs epidemic, although its role in spreading HIV varies widely in the degree of documentation. ${ }^{1,2}$ Labour migration has recently attracted attention as a contributor to the global HIV/AIDS epidemic. ${ }^{3}$ Evidence from several different geographic regions indicates that migrant workers are at elevated risk of acquiring HIV/AIDS. ${ }^{3,4}$ At the end of 2015, an estimated 36.7 million people (34.0-39.8 million) were living with HIV worldwide; up by about $20 \%$ from 2001 level. The number of people dying of AIDS-related causes fell to 1.1 million (940,000-1.3 million) in 2010, down from a peak of 2.2 million (2.1-2.5 million) in the mid-2000s. ${ }^{5}$ Much of that success has come in the past two years when rapid scale-up of access to treatment occurred; in 2015 alone, more than 1 million AIDS related deaths were averted. ${ }^{5}$ Almost half of the deaths from AIDS-related illnesses in 2010 occurred in southern Africa. AIDS has claimed at least one million lives annually in sub- Saharan Africa since 1998. ${ }^{5}$

The epidemic of HIV continues to grow in Nigeria despite efforts to control it. ${ }^{6-8}$ Sentinel surveillance among antenatal clinic attendees increased from $1.8 \%$ in 1991 to $5.8 \%$ in 2001 and $3.6 \%$ in $2009 .{ }^{6}$ Nigeria has the third highest population of people living with human immunodeficiency virus HIV/AIDS globally, only third to India and South Africa. ${ }^{6-8}$ The HIV epidemic in Nigeria has moved from the nascent stage, in which prevalence rate was less than 5\% in all subpopulations, through the concentrated stage, in which prevalence rate is more than $5 \%$ in high risk populations, to the generalized stage, in which prevalence rate is greater than $5 \%$ among women attending antenatal clinics. ${ }^{6}$ Even though HIV is now widespread in Nigeria, evidence strongly suggests that regardless of the stage of the epidemic, the most efficient method to reduce the spread of HIV in the general population is to reduce its transmission among high-risk groups. ${ }^{1,2,5}$ It is therefore crucial to continue strong HIV interventions targeted at high-risk and bridge populations. 2,6,9 As of December 2015, 17 million people living with HIV were accessing antiretroviral therapy, up from 15.8 million in June 2015 and 7.5 million in $2010 .^{5}$ The increasing prevalence of HIV among sex workers in Nigeria has been well documented, as evidenced in the national prevalence of HIV among female sex workers (FSWs), which rose from $17.5 \%$ in 1991 to $22.5 \%$ in 1993 to $36.5 \%$ in 1995 and $30.8 \%$ in $2010 .^{7}$
Correspondence: Usman Sunusi Usman, Department of Public Health, Federal Medical Centre, Birnin Kudu, Jigawa State, Nigeria.

Tel.: 08037601861.

E-mail: usugwarzo@gmail.com

Key words: Human immune-deficiency virus, Long distance drivers, Short distance drivers, risk, sero-prevalence.

Contributions: USU contributed in the design, analysis and interpretation of data as well as drafting the article for intellectual content; AMK contributed in the analysis, discussion and interpretation of data, revises the article critically; YAM participated from conceptualization of the research ideas up to analysis and interpretation of research findings, participated in drafting the articles for intellectual content; ULB contributed in data collection, data analysis, discussion and interpretation of study findings; AIA contributed in the analysis, discussion and interpretation of data.

Conflict of interest: the authors declare no potential conflict of interest.

Funding: none.

Received for publication: 1 September 2018 Revision received: 26 February 2019.

Accepted for publication: 23 April 2019.

This work is licensed under a Creative Commons Attribution NonCommercial 4.0 License (CC BY-NC 4.0).

(C) Copyright U.S. Usman et al., 2019

Licensee PAGEPress, Italy

Pyramid Journal of Medicine 2019; 2:23

doi:10.4081/pjm.2019.23

Meanwhile, many African countries are experiencing generalized epidemic (national HIV prevalence of more than $1 \%){ }^{5}$ But, among those countries with generalized epidemics, a combination of behaviour changes, including reductions in numbers of sexual partners, increases in condom use, and delayed age of first sex, have reduced new infections. ${ }^{5}$ HIV incidence in urban Zimbabwe fell from an extremely high peak of almost $6 \%$ in 1991 to less than $1 \%$ in $2010 .{ }^{10}$ The vast majority of people newly infected with HIV in sub-Saharan Africa are infected during unprotected heterosexual intercourse (including paid sex). ${ }^{5}$ Having unprotected sex with multiple partners remains the greatest risk factor for HIV in this region. ${ }^{5-9}$ Large proportions of people living with HIV are in long-term relationships, $62 \%$ in Kenya and $78 \%$ in Malawi. ${ }^{10}$ And, there are really only two approaches to the epidemic: preventing new HIV infections and providing antiretroviral treatment 
to people who need it. ${ }^{10}$ Commercial sex workers (CSW), LDDs, and men who have sex with men (MSM) constitute the country's main Most at Risk Populations (MARPs), and have a localized HIV/AIDS prevalence as high as $30 \%$ in some states. ${ }^{8}$

Transport workers, in general, share some common characteristics that are likely to put them at high risk of HIV infection. $1,3,10,11$ These include low level of general education and health knowledge, high use of alcohol, reasonably high level of disposable income and common attitude of fatalism. ${ }^{1-3,10,12}$ LDDs hold an important place in the economy as road transport is the main mode of transportation in the absence of working railway system and non-existence of water transportation facilities from one part of the country to the other. ${ }^{6,8,10}$ Due to the long distances they often have to cover, they are repeatedly and constantly separated from their families. ${ }^{2,4}$ They may even have to spend several days at a particular site away from home as part of their work. ${ }^{13,14}$ Furthermore, long-distance truck drivers are vulnerable to sexually transmitted diseases for several reasons; truckers are always on the move, have little or no access to sexual health services, migratory nature of their occupation often disconnect them from family and community, truck drivers rarely interact with orthodox medical practitioners and instead seek the help of quacks and home remedies to cure Sexually Transmitted infections (STIs) and many lack information about STIs and HIV/AIDS and their prevention. ${ }^{1,2,4,15}$

A study conducted in Port Harcourt to determine the sero-prevalence and correlates of HIV infection among LDDs; a total of 100 LDDs were used and the Sero-prevalence of HIV/AIDs was found to be $10 \% .^{16}$ HIV risk perception among transport workers is poor as shown by the 2007 IBBSS. $^{8}$ Only $2.7 \%$ and $6.2 \%$ of LDDs considered themselves as being at high and moderate risk for HIV respectively in 2005. Among the LDDs in Nigeria, a major group that transmits HIV, the use of male latex condoms is generally low and erratic. ${ }^{2,17}$ And, to effectively promote their consistent use, it was necessary to understand the drivers' sexual practices, experience of barriers to condom use and HIV/AIDS-related attitudes. ${ }^{17,18}$

Transport is a social vector in the transmission of the disease similarly to other high risk behaviours such as injecting drug use and commercial sex which fuel the epidemic. ${ }^{1,3}$ Transport sector workers are twice as likely to acquire the HIV infection as workers in 'low-risk' occupations. ${ }^{19}$ And, available literature on HIV risk fac- tors has documented the relationship between mobility and HIV spread in subSaharan Africa. ${ }^{12}$ Migrants' sexual relationships with multiple partners in destination areas are assumed to be the main factor explaining the role of migration in the spread of HIV and other STIs. ${ }^{9}$ The drivers are heterosexual transmitters of HIV mostly occurring along major highway transport nodes within the country, that have links with countries of Middle Africa where the AIDS epidemic is at a more advanced stage. ${ }^{5,10}$

Sunmola found out that, among the long distance truck drivers in Nigeria, the use of male latex condoms was generally low and erratic. ${ }^{17}$ The LDDs along the major high ways in Nigeria noted that their major barriers experienced were that condoms reduced their sexual satisfaction, caused health problems to them, and hindered their sexual interest. ${ }^{15,17}$ More than two third of the drivers knew that condom can prevent them from contacting HIV, but less than one tenth of them use it during sexual intercourse. ${ }^{17}$ And, research has identified condom use as a feasible means to control the spread, particularly in many parts of southern and eastern Africa where the AIDS epidemics have advanced. ${ }^{20}$ Knowledge and attitude towards HIV/AIDS and the practice or otherwise of safe sex contribute significantly to the promotion or reduction of the spread of the disease. ${ }^{20}$ Other important influences are age, religion and level of education. The practice of safer sex with the use of condoms can prevent HIV transmission especially among those with multiple sexual partners. ${ }^{14}$ The high-risk behavior coupled with the mobility of these long-distance truckers makes them potential of spreading HIV not only to different geographical areas but also to their spouses, casual and regular partners. ${ }^{1-3}$

In a study among international truck drivers in Azerbaijan, Injection Drug Users (IDU) was one of the strongest predictors of HIV infection. ${ }^{21}$ As it relates to sexual risk behaviours, according to a study of 1175 Brazilian truck drivers, 95\% of truckers reported having a principal partner and $46 \%$ had any non-regular partner in the last six months, including $32 \%$ who reported commercial partnerships and $24 \%$ who reported occasional partnerships. ${ }^{22}$ Only $9 \%$ of truckers reported consistent condom use during vaginal sex with principal partners and $68 \%$ reported consistent use with occasional partners. ${ }^{22}$ Iranian Study among LDDs have documented specific risk factors for unhealthy sexual behaviours that include, multiple sexual partners, low condom use with female sex workers. ${ }^{23}$

\section{Materials and Methods}

The study was conducted among LDDs in Kano Central Senatorial District. A crosssectional descriptive study design was used. Four hundred and thirty-four questionnaires were administered to the study participants and four hundred and seven questionnaires were fully analysed, given a response rate of about $94 \%$.

A multistage sampling method was used to administer the questionnaires as follows:

Stage I: Simple random sampling was used to select four (Gezawa, Ungogo, Tarauni and Dala) LGAs from the list of fifteen LGAs in Kano Central Senatorial District.

Stage II: A list of all the LDDs motor park who had met the inclusion criteria was obtained. There were eighteen LDDs motor park out of which five were selected by simple random sampling using balloting.

Stage III: From the selected motor parks above, selection of the eligible study participants was done by simple random sampling.

A semi-structured interviewer administered questionnaire, consisting of 3 sections (A to C) was used for data collection in the

Table 1. Socio-demographic profiles of study participants.

\begin{tabular}{lcc}
\hline Variables & Frequency & Percentage \\
Age (years) & & \\
$20-29$ & 53 & 13.0 \\
$30-39$ & 124 & 30.5 \\
$40-49$ & 116 & 28.5 \\
$50-59$ & 87 & 21.4 \\
$60-69$ & 27 & 6.6 \\
Educational Status & & \\
Non-formal & 145 & 35.6 \\
Primary & 122 & 30.0 \\
Secondary & 100 & 24.6 \\
Post-secondary & 40 & 9.8 \\
\hline Marital Status & & \\
Single & 127 & 31.2 \\
Married & 243 & 59.7 \\
Separated & 21 & 5.2 \\
Divorced & 16 & 3.9 \\
No of wives & & \\
1 & 91 & 35.3 \\
$>1$ & 167 & 64.7 \\
\hline Monthly Income & & \\
<N30,000.00 & 51 & 12.5 \\
N30,001.00-50,000.00 & 90 & 22.1 \\
N50,001.00 - 100,000.00162 & 39.8 \\
>100,000.00 & 104 & 25.6 \\
Working Experience & & \\
< 5 years & 126 & 31.0 \\
$5-10$ years & 148 & 36.4 \\
11 - 20 years & 93 & 22.9 \\
>20 years & 40 & 9.8 \\
\hline
\end{tabular}


study.

The outcome variable measured was sero-prevalence and some selected risk factors of HIV/AIDs among the study participants. All the data generated from the study was analyzed using Epi info version 3.5.3. Chi-square test was used to determine significant association between categorical variables. A P-value of $\square 0.05$ was considered significant.

Ethical clearance was obtained from the ethical committee of Kano State Ministry of Health and Ahmadu Bello University Zaria before commencement of the study. The provisions of the HELSINKI declaration were respected.

\section{Results}

The mean age and standard deviation of the study participants was $42.3 \pm 11.2$. About $60 \%$ of the study participants were within the age range of 30-49 years: this age group is very active productively and reproductively. Only about $10 \%$ of the study participants had educational status beyond secondary school. Almost about one third of the study participants were single and among married participants, about two third were from polygamous setting. About one quarter of the study participants had monthly income of more than one hundred thousand naira. Other socio-demographic variables were indicated in Table 1.

The sero-prevalence of HIV/AIDS among the study participants was found to be $12.5 \%$. Majority of the study participants had more than one sexual partner in the last twelve months preceding this study. About $58.5 \%$ of the study participants engaged in extra-marital sex out of which about half of them used condom regularly during the last twelve months preceding this study. Almost one third of the study participants engaged in sex under the influence of drugs and or alcohol. Other identified risk factors among the study participants include history of blood transfusion, history of genital ulcers or urethral discharge as well as history at first sexual intercourse. On the protective factors, only about a quarter among the study participants had participated in HIV/AIDs preventive campaign measures prior to this study. Other protective measures include regular use of condom as stated earlier (Table 2).

Among the study participants, there was a statistically significant association between HIV status and educational status $(\mathrm{P}=0.0338)$, marital status $(\mathrm{P}<0.0001)$ and monthly income. The more you are educated, the less likely you have HIV and those who were married had lowest proportion of
HIV positive respondents. As income increases the chances of becoming HIV positive also increases (Table 3 ).

Furthermore, after adjusting for the confounding effects using logistic regression analysis; educational status of secondary $(\mathrm{AOR}=0.4,95 \% \mathrm{CI}=0.19-0.84)$ and post-secondary $(\mathrm{AOR}=0.25,95 \% \mathrm{CI}=0.13$ $0.97)$, marital status of single $(\mathrm{AOR}=4.25$, $95 \% \mathrm{CI}=1.79-9.31) \quad$ and separated

$(\mathrm{AOR}=6.07,95 \% \mathrm{CI}=5.26-16.45)$, monthly income of $>\mathrm{N} 100,000.00 \quad(\mathrm{AOR}=6.11$, $95 \% \mathrm{CI}=1.53-41.97)$, regular utilization of condom during sexual intercourse in the last twelve month prior to this study (AOR $=0.33,95 \% \mathrm{CI}=0.11-0.72$ ), previous participation in $\mathrm{VCT} / \mathrm{HCT}(\mathrm{AOR}=0.25$, $95 \% \mathrm{CI}=0.16-0.95)$, history of extra-marital sex $(A O R=4.01,95 \% C I=6.07-10.43)$ and previous participation in HIV/AIDs preven-

Table 2. Risk and protective factors of HIV/AIDs among study participants.

\begin{tabular}{lcc}
\hline Variables & Frequency & Percentage \\
No of sexual partners in the last twelve months & & \\
$\quad 1$ & 58 & 14.3 \\
$\quad>1$ & 349 & 85.7 \\
Regular use of condom during extra-marital sex & 202 & 49.6 \\
\hline Previous participation in HCTNCT & 168 & 41.3 \\
Age at first sexual intercourse & 106 & 26.0 \\
$\quad \leq 25$ years & 301 & 74.0 \\
$\quad>25$ years & 137 & 33.7 \\
Sex under the influence of drugs or alcohol & 238 & 58.5 \\
History of extra-marital sex in the last twelve months & 22 & 5.4 \\
\hline History of blood transfusion in the past & 76 & 18.7 \\
History of genital ulcers or urethral discharge & 109 & 26.8 \\
\hline Previous participation in HIV/AIDs preventive measures campaign & &
\end{tabular}

Table 3. Relationship between Socio-demographic variables and HIV status of study participants.

\begin{tabular}{|c|c|c|c|c|}
\hline \multirow[t]{2}{*}{ Variables } & \multicolumn{2}{|c|}{ HIV status } & \multirow[t]{2}{*}{$\chi^{2}$} & \multirow[t]{2}{*}{ P-value } \\
\hline & Yes & No & & \\
\hline $\begin{array}{r}\text { Age (years) } \\
20-29 \\
30-39 \\
40-49 \\
50-59 \\
60-69\end{array}$ & $\begin{array}{c}6 \\
15 \\
12 \\
10 \\
8\end{array}$ & $\begin{array}{c}47 \\
109 \\
104 \\
87 \\
27\end{array}$ & 7.89 & 0.0959 \\
\hline $\begin{array}{l}\text { Educational Status } \\
\text { Non-formal } \\
\text { Primary } \\
\text { Secondary } \\
\text { Post-secondary }\end{array}$ & $\begin{array}{c}17 \\
23 \\
6 \\
5\end{array}$ & $\begin{array}{c}128 \\
99 \\
94 \\
35\end{array}$ & 8.68 & $0.0338 *$ \\
\hline $\begin{array}{l}\text { Marital Status } \\
\text { Single } \\
\text { Married } \\
\text { Divorced } \\
\text { Separated }\end{array}$ & $\begin{array}{c}25 \\
10 \\
7 \\
9\end{array}$ & $\begin{array}{c}102 \\
233 \\
9 \\
12\end{array}$ & 53.48 & $<0.05^{*}$ \\
\hline $\begin{array}{c}\text { No of wives } \\
1 \\
>1\end{array}$ & $\begin{array}{l}18 \\
33\end{array}$ & $\begin{array}{c}67 \\
145\end{array}$ & 0.26 & 0.6129 \\
\hline $\begin{array}{l}\text { Monthly Income } \\
\quad<\mathrm{N} 30,000.00 \\
\quad \mathrm{~N} 30,001.00-50,000.00 \\
\quad \mathrm{~N} 50,001.00-100,000.00 \\
\quad>100,000.00\end{array}$ & $\begin{array}{c}5 \\
8 \\
16 \\
23\end{array}$ & $\begin{array}{c}46 \\
82 \\
146 \\
81\end{array}$ & 10.99 & $0.0118 *$ \\
\hline $\begin{array}{l}\text { Working Experience } \\
\quad<5 \text { years } \\
5-10 \text { years } \\
11-20 \text { years } \\
>20 \text { years }\end{array}$ & $\begin{array}{c}5 \\
7 \\
25 \\
14\end{array}$ & $\begin{array}{c}46 \\
83 \\
137 \\
90\end{array}$ & 3.53 & 0.3172 \\
\hline
\end{tabular}

*Statistically significant difference 
tive measures campaign $(\mathrm{AOR}=0.40$, $95 \% \mathrm{CI}=0.25-0.97)$ remained significant predictors of HIV/AIDs sero-prevalence among study participants (Table 4).

\section{Discussion}

Migration is one of the major contributors to the HIV/AIDS epidemics infection as it increases the number of contacts with sexual partners as well as contacts with other high-risk groups such as commercial sex workers. Studies from different parts of the world suggested that migrants and other mobile individuals act as bridge populations who spread the infections from high-risk to low-risk populations and regions as well as urban to rural areas. ${ }^{17,21,23,24}$

The sero-prevalence of HIV among the study participants was $12.5 \%$. The highest sero-prevalence rate was among the age group of 30-39 years. This finding was less than that of Dibua $U$ in south eastern Nigeria, who reported a sero-prevalence of $19 \%$ among LDDs. ${ }^{25}$ It was about five times greater than findings by Atilola, who reported the sero-prevalence of HIV of $2.4 \%$ among LDDs in South-Western Nigeria. ${ }^{26}$ But, it was close to findings by Azunwo in Port Harcourt who reported $10 \% .{ }^{16}$ Studies from other part of Africa and Asia have also reported different sero-prevalence of HIV among transport workers ranging from low level by Andrew who reported a sero-prevalence of $0.94 \%$ in Port City of Ghana, Sing in India who reported $2.16 \%$, and Pandey in India who Reported $4.6 \%$ to high level by Delany-Moretiwe who reported sero-prevalence of HIV of $26 \%$ among truck drivers in South Africa. ${ }^{18,19,25}$ The sero-prevalence of HIV among the study participants reported in this study was about four times the national average. $5,7,10$

The risk for HIV transmission increases with a higher number of sexual partners, especially when these partners are from high risk group e.g CSW. ${ }^{11,23,24}$ Those who have more than one sexual partner within the last twelve months preceding our studies were four times more likely to be HIV positive compared to those who have one sexual partner among the study participants. Extra-marital sex was found to be an important risk factor for HIV sero-positivity, as study participants who engaged themselves in extra-marital sex were four times at risk of being infected with HIV respectively, as reported in other studies. ${ }^{11,12,17,24}$

About half of the study participants use condom in the last twelve months. This is similar to findings by Sunmola among truck drivers in Nigerian highways, where low and erratic patronage of condom, because of decrease sexual pleasure was reported. ${ }^{11}$ But, findings by Idris on use of condom among transport workers was lower than of this study. ${ }^{15}$ Irregular and erratic use of condoms coupled with multiple sexual partners predisposes these drivers to sexually transmitted infections particularly HIV/AIDs as reported in many studies. $2,11,14,15,17,18,26,27$ The practice of safer sex with the use of condoms can prevent HIV transmission especially among those with multiple sexual partners. ${ }^{14}$

Studies have reported that participation in HCT/VCT was found to decrease the risk of HIV infection among participants more especially those at high risk group. In this study, only two-fifth of the study participants have ever participated in HCT/VCT. ${ }^{20,24,21,26}$ Findings of this study with regards to uptake of HCT was slightly higher than findings of Hassan in Jos and IBBSS of 2010.7,20 This low uptake of HCT among the study participants have a serious implication on transmission of HIV. ${ }^{19}$

The risk of HIV infections increases from age 20-39 years and after that start decreasing gradually. In this study almost one quarter of the participants experienced sexual intercourse before the age of twentyfive years. Early exposure to sexual intercourse increases the risk of transmission of sexually transmitted infections particularly HIV infection as reported in many studies. ${ }^{22}$ It was recorded that in this study more than one quarter of the study participants had sexual intercourse under the influence of drugs or alcohol previously. Sex under the influence of drugs or alcohol may make someone not to adequately protect himself/herself. ${ }^{23}$ This can make someone more vulnerable and further promote infections with sexually transmitted diseases. ${ }^{2,23}$

Table 4. Multivariate (Logistic Regression) Analysis of predictors of sero-prevalence of HIV/AIDS among study participants.

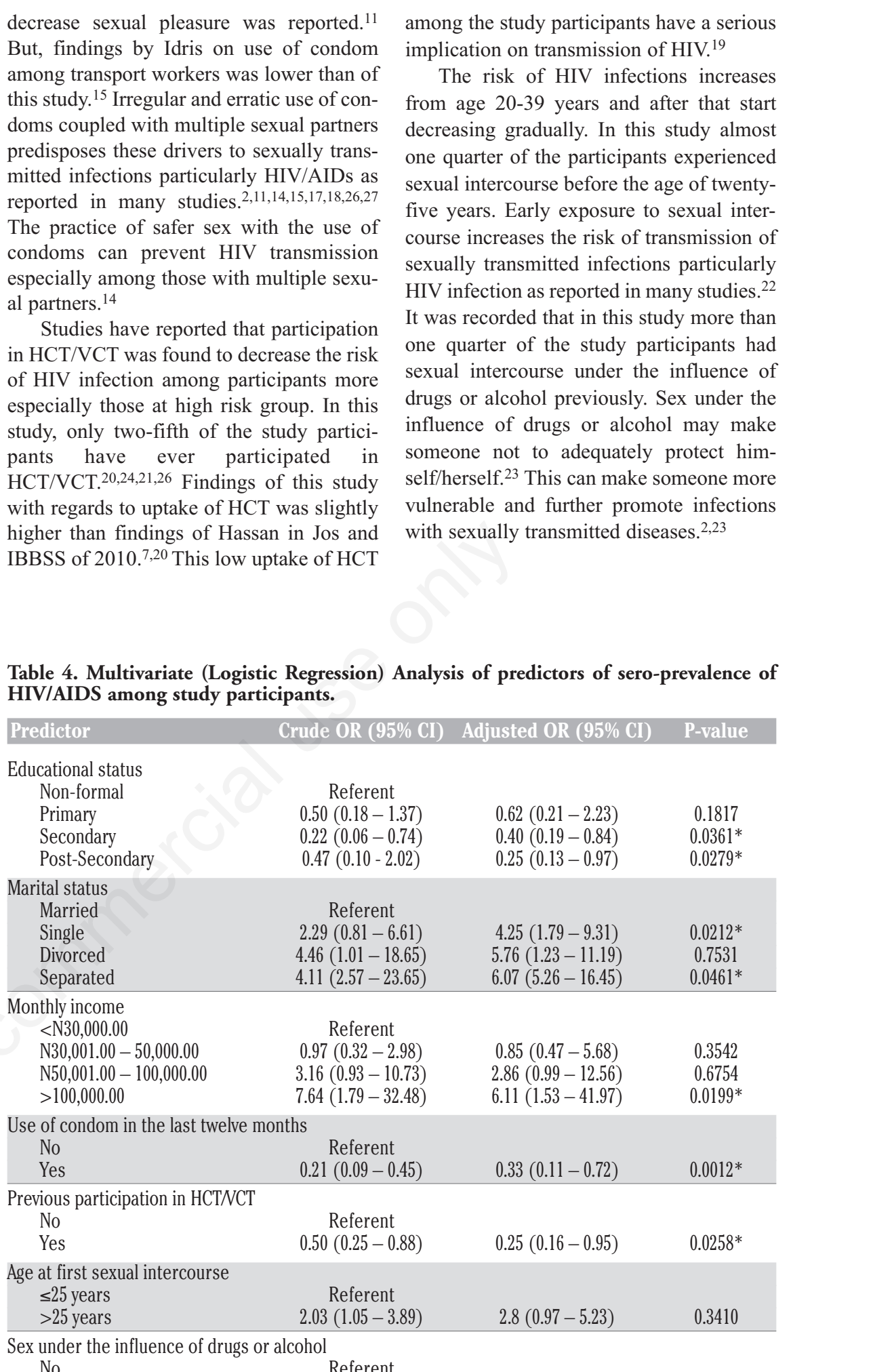

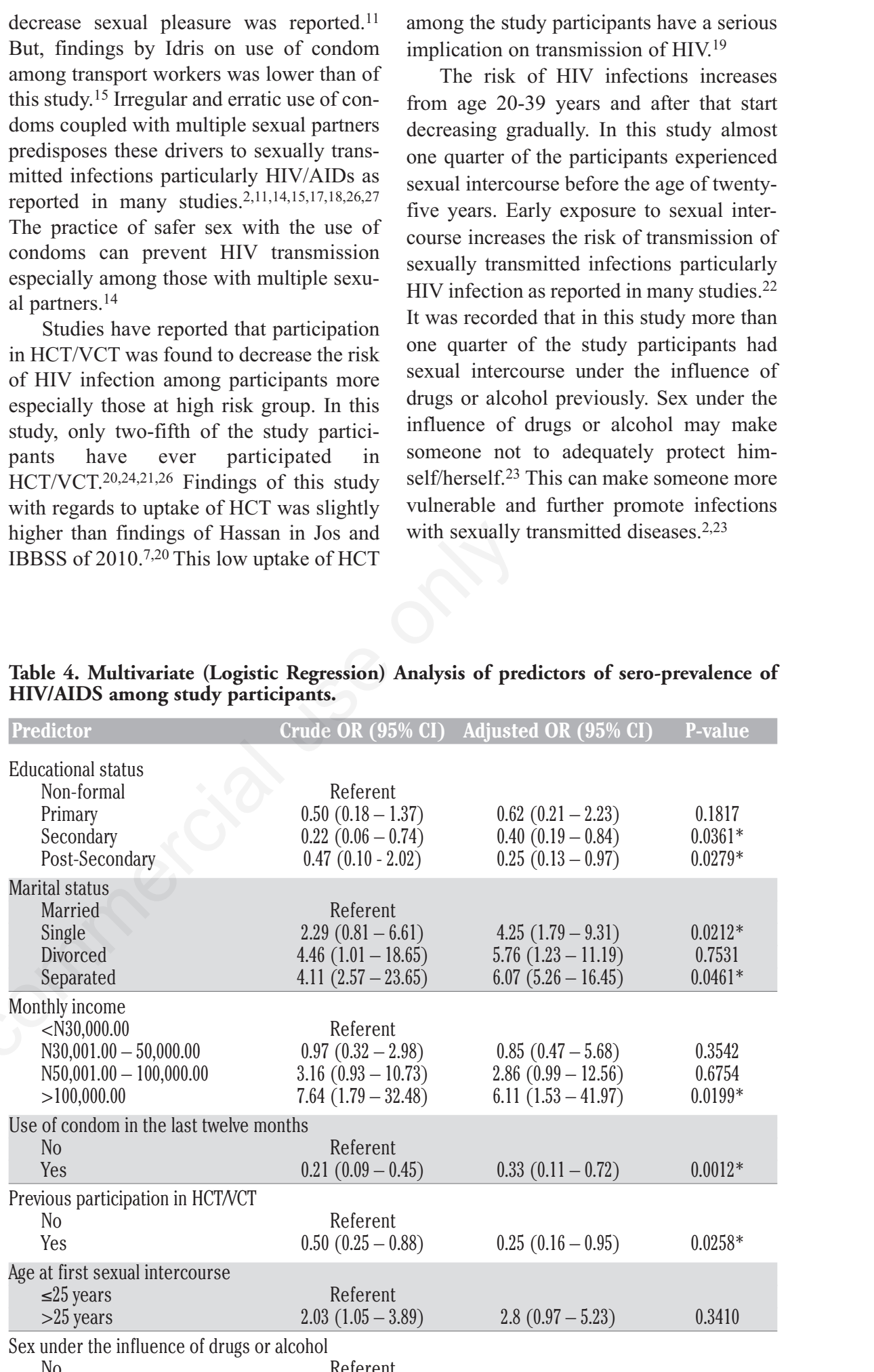

Sex under the influence of drugs or alcohol

$\begin{array}{lr}\text { No } & \text { Referent } \\ \text { Yes } & 4.03(2.10-7.77)\end{array}$

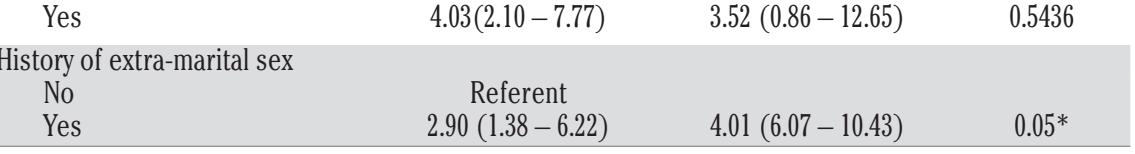

History of genital ulcers or urethral discharge

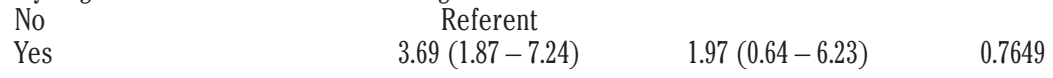

Previous participation in HIV/AIDs preventive measures campaign

$\begin{array}{llll}\text { No } & \text { Referent } & & \\ \text { Yes } & 0.40(0.16-0.95) & 0.33(0.25-0.97) & 0.0007^{*}\end{array}$

*Statistically significant difference. 


\section{Conclusions}

The sero-prevalence of HIV/AIDs was $12.5 \%$ among the study participants: this is more than four times above the national average and thus making the study participants as highly risky group of people in our society. The risk and protective factors identified in the study include educational status, marital status, high monthly income, history of extra-marital sex, use of condom in the last twelve month preceding the study and previous participation of HIV/AIDs preventive measures campaign. Knowing this risk factors will help in addressing the problem of high prevalence of HIV/AIDs among the study participants. Establishment of clinic for treatment of sexually transmitted diseases in a strategic location, scaling up of condom distribution, and effective behavioural change communication were recommended in order to reduce the risk of acquiring HIV infection.

\section{References}

1. Shannon C, Dale S, Sarah V, et al. Sexual and drug use risk behaviour of long-haul truck drivers and their commercial sex contacts in New Mexico. Publ Health Rep 2010;125:52-3.

2. Oyedunni SA, Oladimeji O, Musibau AT. Perception of self-vulnerability to HIV infection among long distance truck drivers in Ibadan, Nigeria. J Basic Appl Sci Res 2011;1:1380-5.

3. Lurie MN. Migration, sexuality and the spread of HIV/AIDs in rural South Africa. Cape Town, South Africa: South African Migration Project; 2004.

4. Coffee M, Lurie MN, Garnett GP. Modeling the impact of migration on HIV epidemic in South Africa. AIDS 2007;21:343-50.

5. Michel S. Report on the global AIDS epidemic. UNAIDS 2013. pp 14-16.

6. Federal Ministry of Health. HIV/Syphilis Sero-Prevalence Survey in Nigeria. 2009. pp 1-2.

7. Federal Ministry of Health (FMOH). Nigeria Integrated Biological and Behavioural Surveillance Survey 2010. pp 1-3.

8. Federal Ministry of Health (FMOH)
Nigeria Integrated Biological and Behavioural Surveillance Survey 2007. pp 1-2.

9. Salomon J. Integrating HIV prevention and treatment: from slogans to impact. PLoS Med 2005;2:16.

10. Magret C, Anthony L, Michel S. Report on the global HIV/AIDS response: Epidemic update and health sector progress towards Universal Access. UNAIDS, WHO, UNICEF. 2011.

11. Lawoyin TO. Condom use with sex workers and abstinence behaviour among men in Nigeria. JR Soc Health 2004;124:230-3.

12. Tobin EA, Okojie OH. Knowledge of AIDS and HIV risk-related sexual behaviour among long distance drivers in Uvwie Local Government Area of Delta State, Nigeria. Nigeria J Commun Med Prim Health Care 2009;21:51-8.

13. Kitara LD, Amone C, Okello C. Knowledge and misconceptions about HIV counseling and testing (HCT) among the post-conflict youths of Gulu, Northern Uganda. A prospective study design. Pan African Med J 2012;12:31.

14. Gomwalk NE, Nimzing L, Mawak JD, et al. Sero-epidemiology of human immunodeficiency virus (HIV) in Plateau State, Nigeria. J Infect Dev Countries 2012;6:860-9.

15. Idris SH, Sambo MN, Obi P. Comportment of heavy goods vehicle drivers in HIV spread along settlements around Kaduna: Kano road transport corridor in Nigeria. Int $\mathrm{J}$ Med Publ Health 2013;3:26-32.

16. Azuonwu O, Erhabor O, FrankPeterside N. HIV infection in long-distance truck drivers in a low income setting in the Niger Delta of Nigeria. J Community Health 2011;36:583-7.

17. Sunmola AM. Sexual practices, barriers to condom use and its consistent use among long distance truck drivers in Nigeria. AIDS Care 2005; 17:208-21.

18. Vuylsteke BL, Ghys PD, Traore M, et al. HIV prevalence and risk behavior among clients of female sex workers in Abidjan, Cote d'Ivoire. AIDS 2003;17:1691-4.

19. Pandey A, Benara SK, Roy N, et al. Risk behaviour, sexually transmitted infections and HIV among long-distance truck drivers: a cross-sectional survey along national highways in India. AIDS 2008;22:81-90.

20. Hassan ZI, Afolaranmi TO, Tagurum YO, et al. Effect of health education on the uptake of HIV counseling and testing among long distance drivers in Jos North Local Government Areas of Plateau State. J Med Trop 2014;16:97103.

21. Atilola GO, Akpa OM, Komolafe IO. HIV/AIDS and the long-distance truck drivers in south-west Nigeria: a crosssectional survey on the knowledge, attitude, risk behaviour and beliefs of truckers. J Infect Publ Health 2010;3:166-78.

22. Lippman SA, Pulerwitz J, Chinaglia M, et al. Mobility and its liminal context: Exploring sexual partnering among truck drivers crossing the Southern Brazilian border. Soc Sci Med 2007;65:2464-73.

23. Maarefvand M, Kassaie B, Ghiasvand $\mathrm{H}$, et al. Sexual and Drug Use Risk Behaviors of Internal Long Distance Truck Drivers in Iran. Iran J Publ Health 2016;45:606-13.

24. Vian T, Semrau K, Davidson HH, et al. HIV/AIDS-Related Knowledge and Behaviors Among Most-at-Risk Populations in Vietnam. Open AIDS J 2012;6:259-65.

25. Dibua U. Socio-Economic and SocioCultural Predisposing Risk Factors to HIV/AIDs: Case Study of Some Locations in Eastern Nigeria. Internet J Trop Med 2009;6:2.

26. Adeoye S. Sexual behaviour, Perception of HIV/AIDS and condom use among commercial motorcyclist in Benin City. Niger Post grad Med J 2005;12:262-5.

27. Awosan KJ, Ibrahim MTO, Arisegi SA, Erhiano EE. Knowledge of HIV/AIDs, risk perception, sexual lifestyle and condom use among drivers in Sokoto, Nigeria. J Infect Dis Immun 2014;6:1925. 